\title{
MIGUEL DE TORRES HENA Y LA CUSTODIA DE TORRE DE LA CATEDRAL DE VALLADOLID (MÉXICO)
}

\section{MIGUEL DE TORRES HENA, MASTER OF THE TOWER MONSTRANCE OF THE VALLADOLID CATHEDRAL (MEXICO)}

\author{
Juan Carlos Ochoa Celestino \\ Museo de Arte Sacro de la arquidiócesis de Guadalajara. México \\ jc9celes3@gmail.com \\ Ricardo Cruzaley Herrera \\ Museo de Arte Sacro de la arquidiócesis de Guadalajara. México \\ mendia_c@hotmail.com
}

\begin{abstract}
Este artículo versa sobre la historia de la construcción de la custodia de asiento de la catedral de Valladolid en México, obra del platero mexicano Miguel de Torres Hena y finalizada en 1608, evidenciando con ella la existencia de esta tipología en tierras novohispanas.

Palabras clave: custodia de asiento; platería mexicana; siglo XVII; catedral de Valladolid; México.

This paper deals with the history of the construction of the tower monstrance of the Valladolid Cathedral in Mexico, a work by the Mexican silversmith Miguel de Torres Hena in 1608, showing the existence of this model in New Spain.

Keywords: tower monstrance; mexican silverwork; $17^{\text {th }}$ century; Valladolid Cathedral; Mexico.
\end{abstract}

Son los documentos que se van localizando en distintos acervos y archivos los que, al salir a la luz, nos brindan elementos muy valiosos con los cuales podemos formarnos una idea cercana a la realidad y las circunstancias que tuvieron ciertas obras de platería que, en algún momento de la historia, se acuerdan concertar y elaborar por instituciones como el cabildo eclesiástico de la catedral de Valladolid. 
Como sabemos, el material con el que están realizadas estas obras tiene la particularidad de ser un factor mucho más importante para su conservación o no que la función misma de la pieza para la que fue creada o los valores estéticos que conlleva. Pues aunado al tipo de material y la propiedad de este mismo de poder ser reutilizado, permite que el deterioro ocasionado por el uso en ocasiones inadecuado, el cambio de gustos o la urgencia económica hagan de estas obras de orfebrería blanco de miradas ansiosas de contar con piezas en los estilos de mayor vigencia y a la moda del momento, o a la posibilidad de poder disponer de su valor en metálico para solucionar algún imprevisto.

Un alto porcentaje de esta producción de siglos anteriores que el gremio de plateros elaboró en América y España sucumbió ante estos avatares, por lo que ahí radica la importancia de los documentos que nos hablan sobre las piezas, muchas de ellas importantes y destacadas, y de las cuales solo nos queda la referencia escrita.

Y esto es lo que sucede con la custodia de asiento de la catedral de la antigua Valladolid, en la actualidad Morelia (México), la cual podemos conocer gracias al expediente localizado en el Archivo Histórico del Arzobispado de Morelia, donde se reúnen documentos relativos a la contratación y realización de esta obra, que para su tiempo fue de particular relevancia, ya que se trataba de la pieza de mayor importancia que tuvo el tesoro catedralicio destinado a la procesión del Corpus Christi. Vamos, por tanto, a estudiar y analizar todos estos documentos para así poder conocer las maneras y los gustos de un periodo particular en la consolidación del poder que el cabildo eclesiástico iba adquiriendo y su disposición para la celebración del culto divino en el extenso y rico obispado de Valladolid en la Nueva España.

Visto desde nuestra actual perspectiva esta obra llama la atención por su tipología, pues, aunque para España las custodias de asiento fueron habituales en toda su geografía, no lo fue así para la Nueva España ni mucho menos para la Nueva Galicia, pues pocos son los testimonios tenidos al respecto y menos los que se han conservado. Por lo tanto, es una tipología casi inexistente en América en la actualidad, pues solo el ejemplar de la catedral de Santo Domingo y el que presentamos aquí son conocidos y se conservan en todo este territorio, a pesar de la brillante historia de la platería hispanoamericana y la existencia de plateros capacitados para labrar piezas de esta importancia. Las causas podrían estar fundamentalmente en la desaparición de estas piezas por los avatares históricos, como quedó expresado con anterioridad, y por la falta de una investigación profunda de la documentación existente. Es gracias a la búsqueda en los archivos como hemos podido sacar a la luz el importante caso de la catedral de Valladolid que seguidamente analizaremos de manera pormenorizada.

En la actualidad, la catedral de Morelia cuenta con una custodia de asiento que puede considerarse hasta el momento la única conservada de la Nueva España y la Nueva Galicia. Concretamente se trata de una obra tardía, fechada en 
1774, diseñada por Isidoro de Balbás, hijo adoptivo de Jerónimo Balbás, y construida por el maestro platero vecino de la ciudad de México José del Castillo (Figura 1$)^{1}$. No obstante, no será de esta pieza concreta sobre la que versará nuestro estudio, sino de la que se hizo con anterioridad, en plena época de la Contrarreforma, cuando esta tipología tuvo un importante auge en los reinos hispanos, y posiblemente también en América, aunque hoy día su huella pase totalmente desapercibida. Una obra que podemos conocer a través de los restos que conserva la dieciochesca y la localización en el Archivo Histórico del Arzobispado de Morelia de un largo expediente con todos los pormenores que acontecieron para su construcción ${ }^{2}$.

Sabemos que la catedral tuvo a bien tener una custodia de asiento desde fines del siglo XVI, siguiendo el ejemplo de otras catedrales importantes de la Nueva España, como eran la de Puebla de los Ángeles o la de la Ciudad de México. De hecho, la primera prueba documental que tenemos de la intención de construir una custodia por parte de la catedral de Valladolid la hallamos en las actas del cabildo catedralicio de 1597, cuando el deán don Pedro Díez Barroso, junto a sus capitulares, apremian la necesidad de mandar hacer una custodia de plata para la procesión del Corpus Christi, la cual debía ser a la manera y forma de la de la catedral de la Ciudad de los Ángeles ${ }^{3}$.

Sin embargo, no será hasta cinco años más tarde cuando comience el proceso de la contratación de la obra. El 12 de noviembre de 1602 se comienza a mover la maquinaria para materializar dicha idea. En este día, el deán don Francisco Gallegos Osorio y sus capitulares apoderaron a don Melchor Gómez de la Cadena ${ }^{4}$, maestrescuela de la catedral de México, y al licenciado don Melchor Gómez de Soria, chantre también de la misma institución, para que pudieran gestionar la fabricación de una custodia de torre para la catedral de Valladolid ${ }^{5}$.

Sin duda, el cabildo de la catedral vallisoletana acudió a dos importantes personajes del clero mexicano, dos miembros del cabildo de la catedral de México

${ }^{1}$ OCHOA CELESTINO Juan Carlos y CRUZALEY HERRERA, Ricardo: "José Pantaleón Toscano y la lámpara mayor de la catedral de Guadalajara", en Aurea Quersoneso. Estudios sobre la plata Iberoamericana. Siglos XVI-XIX. León, 2014, pp. 205-226.

2 Archivo Histórico del Arzobispado de Morelia (A.H.A.M.), sección Capitular, 2-2.1-3-1, ff. 10f-29f.

3 A.H.A.M., Libro de actas de cabildo, 19-12-1597.

${ }^{4}$ CASTILlO FLORES, José Gabino: La Catedral de México y su Cabildo Eclesiástico. Zamora (México), 2013, p. 175.

${ }^{5}$ La escritura se hace ante el escribano público Francisco Menen Alcaraz y asisten los siguientes miembros del cabildo catedralicio: don Pedro Díaz Barroso, chantre; don Diego de Orduña, maestrescuela; Joaquín Gutiérrez; el licenciado Antonio de la Parra y Gamboa; Domingo Pérez del Castillo; el doctor Diego Díaz, racionero; y los prebendados José Díaz y Frutos del Castillo. Fueron testigos de esta escritura Alonso de Cáceres y Benito Pérez. 
que con anterioridad habían formado parte del de Valladolid. Este antecedente seguramente influyó para que se les considerara las personas más idóneas a quienes solicitar su ayuda en esta encomienda. Don Melchor Gómez de la Cadena en ese momento era el maestrescuela de la catedral de la Ciudad de México y había pasado por el cabildo de Valladolid entre los años 1570 y 1575, siendo incluso promovido luego como deán de la catedral de los Ángeles, del obispado de Tlaxcala, y que tuvo que ver con la elaboración de la custodia de esa sede. Por su parte, Melchor Gómez de Soria había sido deán en la catedral de Valladolid en 1599, solicitando la chantría de la de México por muerte de Alonso Larios, de la que tomó posesión en 1600. El que estos personajes radicaran en la Ciudad de México aumentaba las ventajas que desde Michoacán requerían para estar al pendiente de la elaboración de este proyecto, por lo cual es entendible que se les otorgara el poder para realizar esta obra tan importante. Aunque ninguno de los canónigos de Valladolid estará al cuidado del trabajo, se hacen algunas precisiones que son importantes destacar, como es el hecho de que se mencione que la custodia tendrá que labrarse teniendo como modelo la de la ciudad de los Ángeles, del obispado de Tlaxcala, y a la cual se le "deben enmendar los defectos que se han advertido después de hecha". También se les da libertad completa a los canónigos de México para elegir a los plateros que harían el trabajo. Y, por supuesto, y en vista de estas precisiones, los apoderados eligieron al maestro que había labrado la custodia de Puebla de los Ángeles, Miguel de Torres Hena, el cual había terminado la torre de esta última catedral hacía dieciocho años, por lo tanto se aseguraban que se cumpliera el mandato de los capitulares vallisoletanos ${ }^{6}$.

Tras su elección se concierta en la Ciudad de México la custodia de plata con el referido platero el 13 de febrero de 1603. Ambos canónigos junto al platero acuerdan labrar una custodia de plata de un peso de quinientos treinta marcos poco más o menos, y cuya traza debía seguir a aquella consensuada y firmada por el cabildo de Valladolid y refrendada por el notario Francisco Menen. Debía ser de cuatro cuerpos, siendo el primero del orden dórico, el segundo jónico y el tercero corintio, sin hacer alusión a los soportes del cuarto y último de estos cuerpos. Se insiste en que fuera bien labrada, soldada y ensamblada y que oficiales experimentados dieran su parecer una vez estuviese acabada la obra.

Lo más interesante son las condiciones que se recogen en el contrato, que nos permiten tener una idea aproximada de cómo debía ser la torre y localizar las piezas hoy conservadas en la actual. Así, se habla que en el banco del primer cuerpo llevara seis historias del Antiguo Testamento, las cuales debían ser: Abraham adorando a los tres ángeles, la serpiente del desierto, el maná, el sacrificio de Abel con el cordero encendido, la comida de Jacob a su padre Isaac con la que ganó la

${ }^{6}$ GARDUÑO PÉREZ, María Leticia: "La custodia en forma de torre de la Catedral de Puebla", en El Sueño del Dorado. Estudios sobre plata en Iberoamérica. Siglos XVI-XIX. León, 2012, pp. 265-273. 
primogenitura, y José dando el trigo y dinero a sus hermanos. Relieves que presentan afinidad con las estampas circulantes en la época, algo muy popular en el arte hispanoamericano, y que, en el caso concreto del relieve de las ofrendas de Abel y Caín, se pueden vincular al modelo que presenta sobre el tema Johan Sadeler I (Figura 2). Al igual que su modelo poblano, en los basamentos de las columnas aparecerían los veinticuatro profetas del Antiguo Testamento, de los que aún se conservan diecinueve placas en la actual custodia donde se reproducen los profetas mayores y menores, todos ellos de perfil y con una filacteria donde se recoge su nombre: "ABA/ CV" (Figura 3).

Debía este primer cuerpo tener una cerca - una balaustrada-, el piso ser jaquelado y sobre él reproducirse la Cena del Señor, solicitándose que las figuras fuesen de gran perfección, grandes y como mejor se pudiera labrar. Se especifica que delante de cada dos columnas se ubicara una figura de bulto redondo, en concreto Melquisedec con pan y vino en sus manos, David con un arpa, Ezequiel comiéndose un libro, Habacuc con la cesta y la olla, Zacarías con una jarra de vino y pan, y, finalmente, Michael, quien debería sostener un racimo de uvas en las manos. Sorprende entre estas figuras, la fuerza expresiva de Habacuc, con la cesta de pan, faltándole hoy día la olla, que sin duda emparenta con la mejor escultura romanista de la época (Figura 4). Por otra parte, las columnas soportarían el arquitrabe, con su friso y cornisa sosteniendo la bóveda que cobijaba a la Santa Cena. Esta bóveda debía ser de media naranja con casetones y serafines, y en la clave central un racimo de uvas.

En el arquitrabe de estas columnas debía colocar seis historias del Nuevo Testamento, concretamente: la comida de los cinco panes en el desierto o Jesús servido por los ángeles en el desierto, Jesús partiendo el pan en la cena de Emaús (Figura 5), la multiplicación de los panes y los peces (Figura 6), Jesús en la orilla del mar comiendo el pez asado y el pan o la segunda pesca milagrosa, el convite en casa de Zaqueo y la última escena las bodas de Caná. De nuevo, en estos relieves se advierte la estampa como fuente de inspiración, además del buen hacer del platero.

$\mathrm{Y}$ en los resaltos del dicho friso, correspondiendo con los espacios libres de abajo, irían veinticuatro figuras pequeñas de santos: San Bernabé, San Lucas, San Laurencio, San Blas, San Apolinar, San Esteban, San Isidro, San Ildefonso, San Leandro, Santa Clara, Santa Catalina de Siena, Santa Lucía, Santa Marta, Santa María Magdalena, San Ignacio y San Martín obispo. Sobre las columnas, el friso y el arquitrabe se levantarían doce pirámides como remates y, entre ellas, los apóstoles San Pedro, San Pablo, Santiago el Mayor, Santiago el Menor, San Juan Evangelista y San Andrés.

Luego vendría el segundo cuerpo que sería de orden jónico, donde las columnas seguirían el patrón de las primeras. Es en este nivel donde va colocado el viril para exponer al Santísimo Sacramento, con forma de linternilla sobre una peana o base con doce figuras, seis en encasamentos y seis por remate. Las primeras 
debían ser los Doctores de la Iglesia San Ambrosio, San Agustín, San Jerónimo, San Gregorio Magno, Santo Tomás de Aquino y San Atanasio, y las figuras del remate, seis ángeles con instrumentos musicales. Da a entender que entre los nichos que llevan estas figuras irían unas pilastras a manera de términos, que sostendría el "Ara" para el Santísimo, lo que nosotros conocemos como viril, el cual debía de ir muy pulido como si fuera de oro, labrado de manera curiosa y llevar su resplandor de rayos de plata dorados.

Menciona que el friso de este segundo cuerpo debía ser labrado "al romano" con cosas muy pulidas, con su bóveda acorde a la del primer cuerpo, sus columnas que se rematarán en pirámides y en medio de ellos seis figuras representando a San Joaquín, Santa Ana, Zacarías, Santa Isabel, San Juan Bautista y el rey David, propios de la genealogía de la Virgen María.

El tercer cuerpo de orden corintio tendría seis columnas, rematadas por figuras redondas, y debajo de la bóveda la representación de Dios Padre mirando hacia Nuestra Señora de la Concepción entronizada en su centro. Además, debería ir ornado y rodeado de nubes y serafines con una letra de la Tota Pulcra rodeando la imagen de María con resplandor y las doce estrellas apocalípticas, y cuya estrella central debía reproducir "Estella Marie".

El cuarto y último cuerpo debía estar, según la traza, con una imagen de San José, cercada por seis columnas de términos, que soportarían una cúpula de media naranja muy pulida y labrada, sobre la cual se alzaría la Resurrección del Señor muy bien labrada. Los términos llevarían remates sólidos y pirámides o lo que pudiera ser mejor, además de acompañarse de las virtudes teologales, la $\mathrm{Fe}$ (Figura 7), la Esperanza y la Caridad (Figura 8), además de tres de las cardinales, en concreto la Justicia, la Fortaleza y la Templanza. Todas ellas con ese porte de matrona romana, portando sus atributos iconográficos y de una buena calidad en su hechura.

Además, se señala que la custodia debía ir sobre una peana bien labrada de martillo, con alma de madera y una cerca para que la moldura no se deshiciese, con una altura de cuatro dedos, o, lo que sería lo mismo, unos diez centímetros.

En estas condiciones, además, se detalla que la custodia debía rondar los quinientos treinta marcos de plata, y, si se producía una demasía en este peso, se debía paralizar la obra. La finalización de la custodia se establecía para la fiesta del Corpus Christi del año 1606, por lo que se estableció para realizar tan magno encargo la duración de cuatro años. La cotización solamente del trabajo realizado por el platero sin incluir el material sería de 20 pesos el marco de plata labrada, la cual la pondría la catedral vallisoletana, estableciendo el marco de plata en 28 pesos con todo y material. El platero en este caso propuso un esquema de pagos que incluían un anticipo de 1.500 pesos al iniciar el trabajo y pagos de 2.000 pesos con fechas del 19 de febrero y el 19 de agosto por los siguientes años hasta 1606; la diferencia que quedara se pagaría en dos tantos, uno para la Pascua de Navidad y el otro en la Pascua de Resurrección del siguiente año. 
Y como era preceptivo en este tipo de contratos, se compromete el platero a que su trabajo sea revisado por dos plateros que determinasen su calidad y su ejecución de acuerdo con el proyecto planteado en esta escritura, comprometiéndose el platero a entregarla armada personalmente en Valladolid. Además, para salvaguardar esta contratación, el platero se comprometía a respetar los términos de la misma, haciendo constar que si los incumplía se le descontarían dos pesos de oro por cada marco y con la posibilidad que fuese otro artista el que finalizara la misma.

Finalmente, la obra fue entregada seis años después, dos más de lo estipulado en la contratación, pues Miguel de Torres de puño y letra redacta una carta dirigida al cabildo de Valladolid ${ }^{7}$, avisando de la terminación de la obra y mencionando también que su tasación se realizó el 19 de mayo de 1608 ante el escribano real Pedro de Lugo, actuando como representante del cabildo Alonso de Miraval. El peso fue tasado por los plateros nombrados por Miraval, Cristóbal Tercero y Pablo de Toledo, y por la parte del autor Pablo Recio y Juan Piquero, declarando los cuatro que la obra pesó 570 marcos, 40 marcos más que lo acordado en la escritura, aunque esa demasía se justificaba por el resultado obtenido. Además, Miguel de Torres solicitaba que le fuese liquidado el saldo que aún quedaba pendiente y que su sobrino y dos españoles serían los que marcharían a Valladolid a entregar la custodia armada por "no ser posible dejar la Caja Real a partida de galeones", lo que viene a respaldar lo publicado por la doctora Carmen Heredia, quien concluye que seguía actuando como marcador y ensayador desde 1606 hasta agosto de ese mismo año de 1608 en el que se da el nombramiento a su hijo Miguel de Hena Torres del cargo de ensayador, veedor y marcador de la Ciudad de México ${ }^{8}$.

Alonso de Miraval remitió un informe igualmente al cabildo vallisoletano9, donde además informaba que la custodia estuvo expuesta dos días en la casa del platero y que vinieron tanto civiles como religiosos de todos los lugares cercanos, los cuales externaron su beneplácito por lo bien ejecutada que quedó realizada dicha custodia, inclusive de personas que habían conocido en España otras custodias como la de Madrid, Toledo y Sevilla, que, aunque algunas con más plata, ninguna con el "artificio, obra y pulicia" que esta tiene, además de haber sido un acierto el decidir que se dorase, aunque este punto no estuviese anotado en la escritura, pero al parecer se acordó cuando el trabajo estaba ya comenzado.

Sin lugar a dudas, esta obra de nuevo representaba un hito en la carrera artística de Miguel de Torres, quien 18 años antes ya había demostrado su valía con la

${ }^{7}$ A.H.A.M., sección Capitular, 2-2.1-3-1, f. 23 f.

${ }^{8}$ HEREDIA MORENO, Carmen: "Precisiones sobre los cargos públicos de la platería en el Virreinato de Nueva España (1527-1650)", en Estudios de platería: San Eloy 2010. T. 10. Murcia, 2010, pp. 313-318.

9 A.H.A.M., sección Capitular, 2-2.1-3-1, ff. 24f-25f. 
custodia que había labrado en la Puebla de los Ángeles y que era prácticamente idéntica. Los antecedentes a estas piezas en América las encontramos en la primigenia custodia de asiento de la catedral de Santo Domingo, obra sevillana de hacia 1540, y en otras que conocemos documentalmente, como la que fue traída por fray Diego de Chávez desde España entre los años 1560 y 1570 para el convento agustino de Yuririapundaro ${ }^{10}$. Obras renacentistas que son buena prueba del trasvase de una tipología a tierras americanas, y que, como ocurrió con otras piezas, luego sirvieron de ejemplo para la ejecución de obras similares en los talleres americanos. Y la ausencia de un mayor número de custodias de asiento en suelo mexicano no puede hacernos pensar que no hubo una disposición a su construcción, pues los ejemplos de Morelia, de la Puebla de los Ángeles o la Ciudad de México ratifican la importancia que se les concedió, cuanto más por ser una costumbre muy española que, como sucedió con otras tradiciones, su uso estuvo presente en la celebración de la fiesta del Corpus Christi. De hecho, la custodia de asiento de la catedral de Puebla de los Ángeles ejecutada por los hermanos Juan y Miguel de Torres Hena en el año de $1585^{11}$ es, sin duda, la primera referencia de la participación en la construcción de esta tipología por los plateros establecidos en América; relevante es además, pues sería en esta época cuando comenzaban las platerías americanas a emanciparse de la dependencia peninsular al recibir estos importantes encargos que les permitirían proponer soluciones novedosas. Una pieza celebrada y renombrada en toda la Nueva España, pues, como ya comentamos en un principio, fue el modelo a seguir por el cabildo vallisoletano, hasta el punto de que el cabildo pagó al canónigo Antonio de la Parra y Gamboa por "lo que dio en la ciudad de los Ángeles por los modelos de madera para la custodia"12. Un modelo lignario que sirvió sin duda para la labra de la nueva torre, algo que igualmente se constata con la descripción que se tienen de la poblana. Una custodia de tres pisos, de orden corintio todos sus soportes y un cuarto con términos, por lo que la adopción en la vallisoletana de los tres órdenes superpuestos perfecciona en sentido clásico el modelo de Puebla de los Ángeles. Un platero, Miguel de Torres Hena, que, según Carmen Heredia, pudo haberse formado con Gabriel de Villasana, con el que posiblemente tuvo la oportunidad de conocer la $\mathrm{De} \mathrm{Va}$ ria Conmensuración de Juan de Arfe, una fuente de inspiración básica para este tipo de construcciones argénteas, dan como resultado la magnífica ejecución de obras de las cuales apenas podemos darnos una idea por los remanentes físicos que perduran.

Desafortunadamente se desconoce el paradero de la torre argéntea de Puebla, así como de otras como aquella que también tuviera la catedral metropolitana de

${ }^{10}$ ESCOBAR OLMEDO, Armando: "La custodia de plata del convento agustino de Yuririapundaro", Tzintzun, 8, 1987, pp. 115-120.

${ }^{11}$ GARDUÑ̃ PÉREZ, M. L.: "La custodia en forma...”, op. cit., pp. 265-271.

12 A.H.A.M., Libro de actas de cabildo, 13-7-1607. 
México hacia finales del siglo XVI, la cual conocemos a través de dos dibujos publicados por Artemio del Valle Arizpe, quien los localizó en un libro de inventarios del templo de $1842^{13}$. Y aunque es un libro tardío, de uno de esos dibujos dice que corresponde a la obra realizada en tiempos del arzobispo Juan Antonio Vizarrón (1682-1747), por lo que nos permite ratificar la continuidad en la tipología de torre en los obradores locales.

Y para corroborar esta teoría tan solo habría que mencionar la actual custodia de asiento de la catedral de Valladolid, que mencionábamos en un principio, y que fue construida en 1774 por el platero mexicano José del Castillo según un diseño de Isidoro de Balbás. En su fabricación se invirtió la mayor parte de la plata de la antigua pieza de Miguel de Torres reutilizando y colocando en lugares destacados algunos de los relieves y esculturas que fueron de la anterior custodia. Por todo ello, y por la falta aún de un estudio profundo, el cual realizaremos de este último ejemplar, podemos comprobar cómo la tipología de custodias de asiento también estuvo presente en la platería mexicana desarrollándose y logrando carta de identidad, pero que, debido a los diferentes avatares históricos, hoy día ha llegado a nosotros apenas algún ejemplo físico, aunque en futuras investigaciones el catálogo de estas obras y la nómina de sus artífices podrá ampliarse y darnos una visión mucho más completa de este ostentoso fenómeno de la platería hispanoamericana.

Fecha de recepción: 27 de septiembre de 2016

Fecha de aceptación: 1 de febrero de 2017

${ }^{13}$ DEL VALLE ARIZPE, Artemio: Notas de Platería. México, 1941, pp. 290-317. 


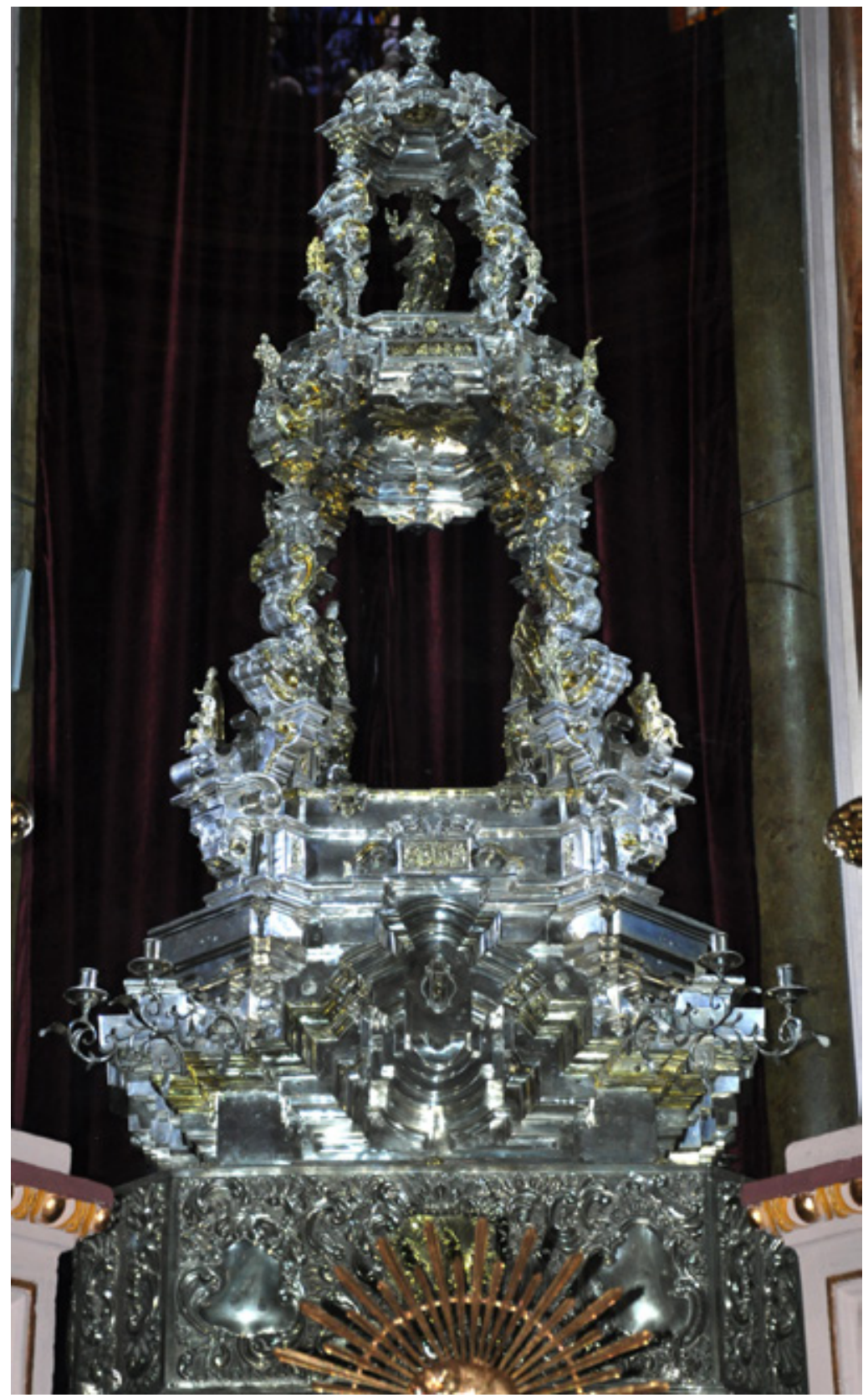

Figura 1. Miguel de Torres Hena y José del Castillo, Custodia de asiento, 1608-1774, catedral de Morelia (México). Foto: autores. 


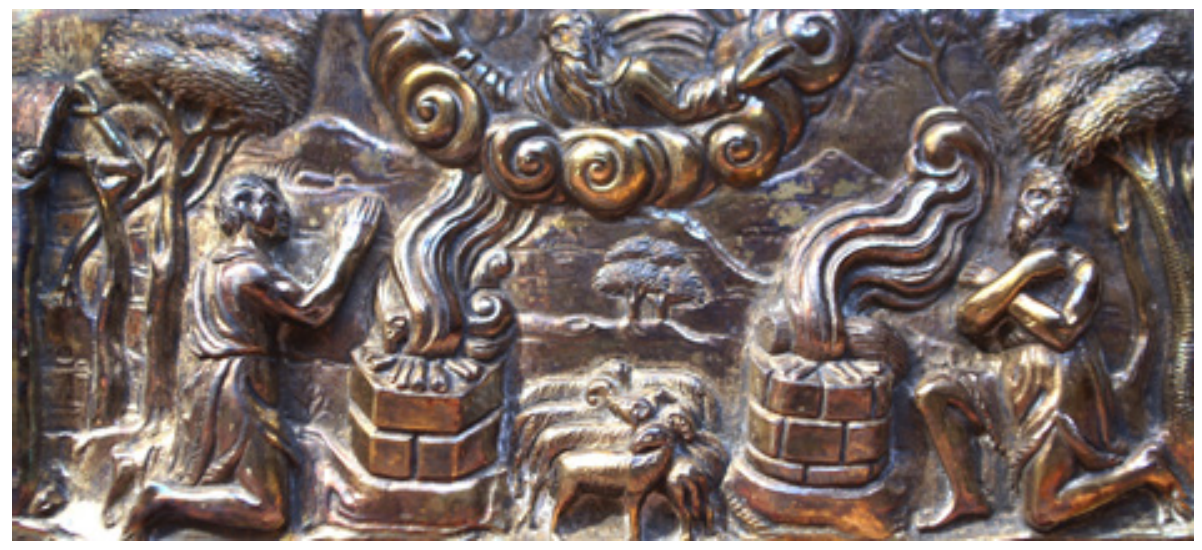

Figura 2. Miguel de Torres Hena, Custodia de asiento, relieve de los sacrificios de Abel y Cain, 1608, catedral de Morelia (México). Foto: autores.

Figura 3. Miguel de Torres Hena, Custodia de asiento, relieve de Habacuc en su atalaya, 1608, catedral de Morelia (México). Foto: autores.

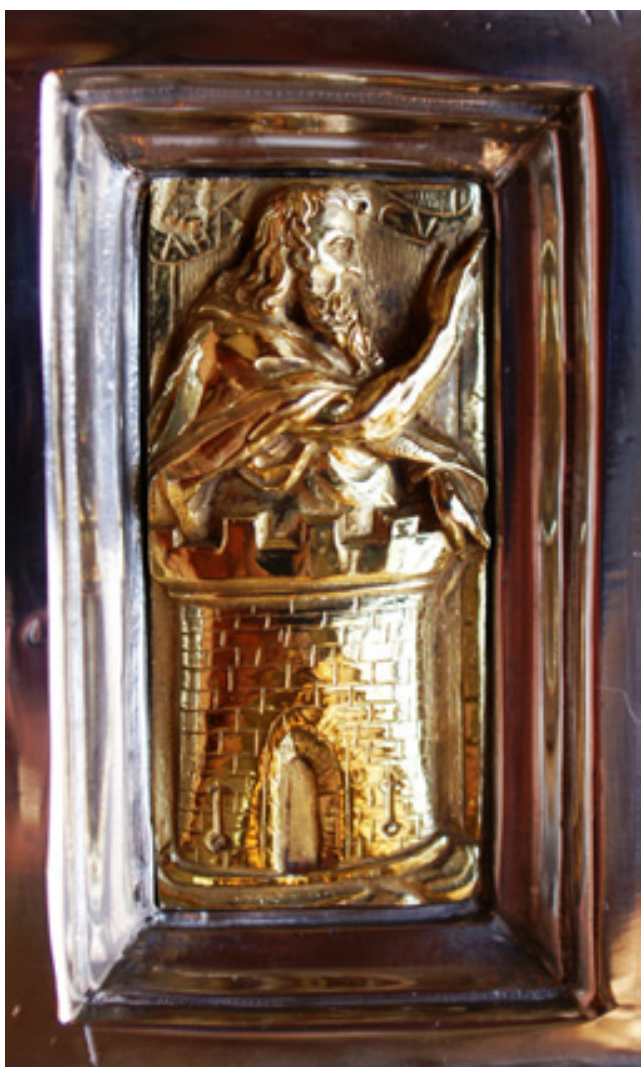

LABORATORIO DE ARTE 29 (2017), pp. 229-242, ISSN 1130-5762 e-ISSN 2253-8305 - DOI http://dx.doi.org/10.12795/LA.2017.i29.11 


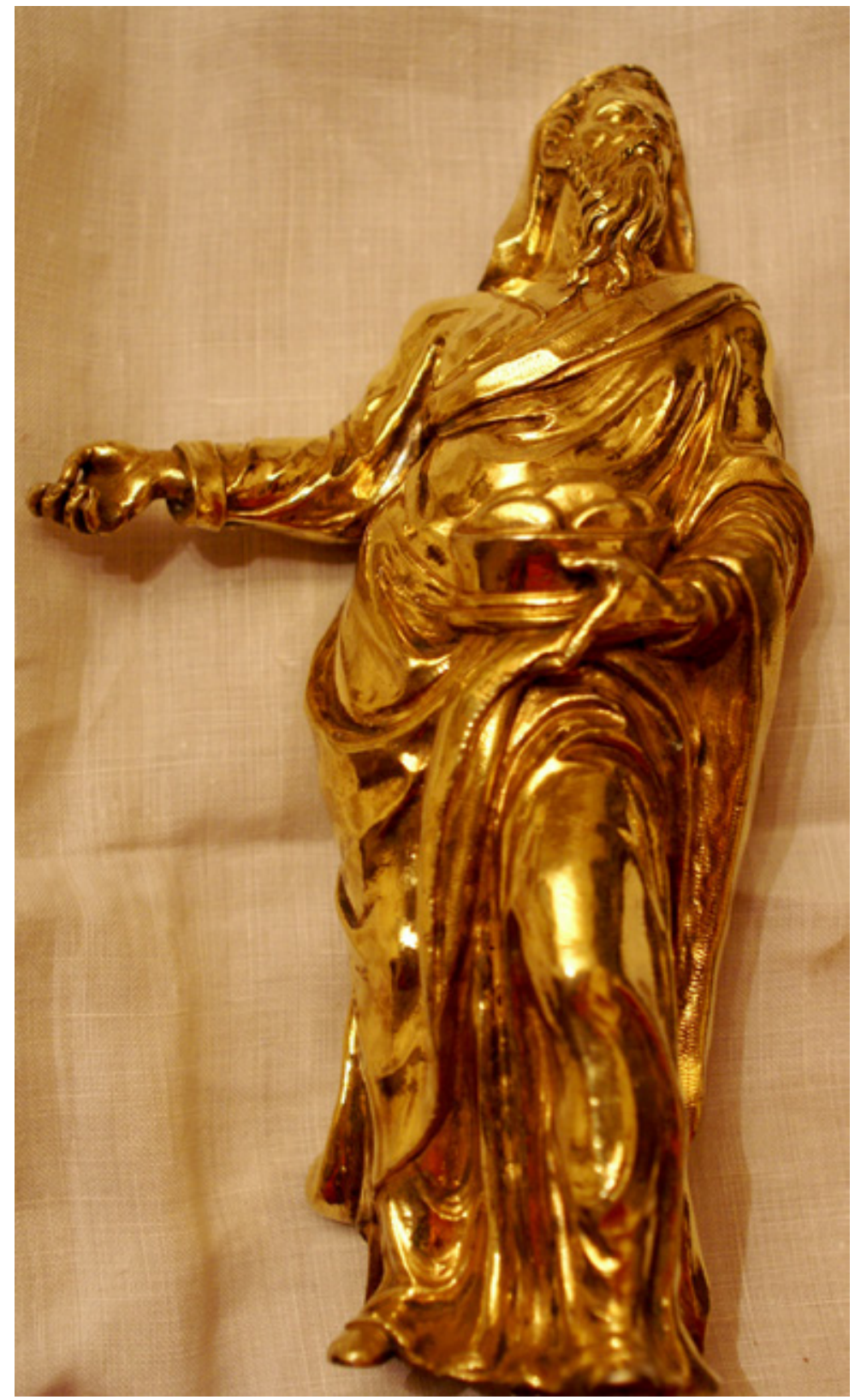

Figura 4. Miguel de Torres Hena, Custodia de asiento, Habacuc con su cesta de pan, 1608, catedral de Morelia (México). Foto: autores. 


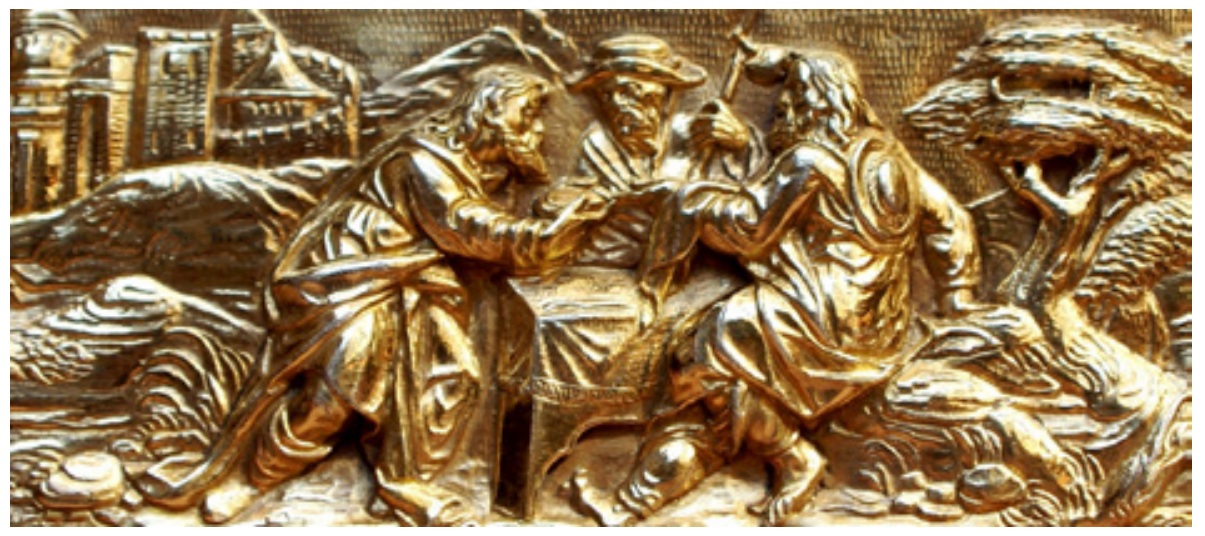

Figura 5. Miguel de Torres Hena, Custodia de asiento, relieve de Jesús partiendo el pan en Emaús, 1608, catedral de Morelia (México). Foto: autores.

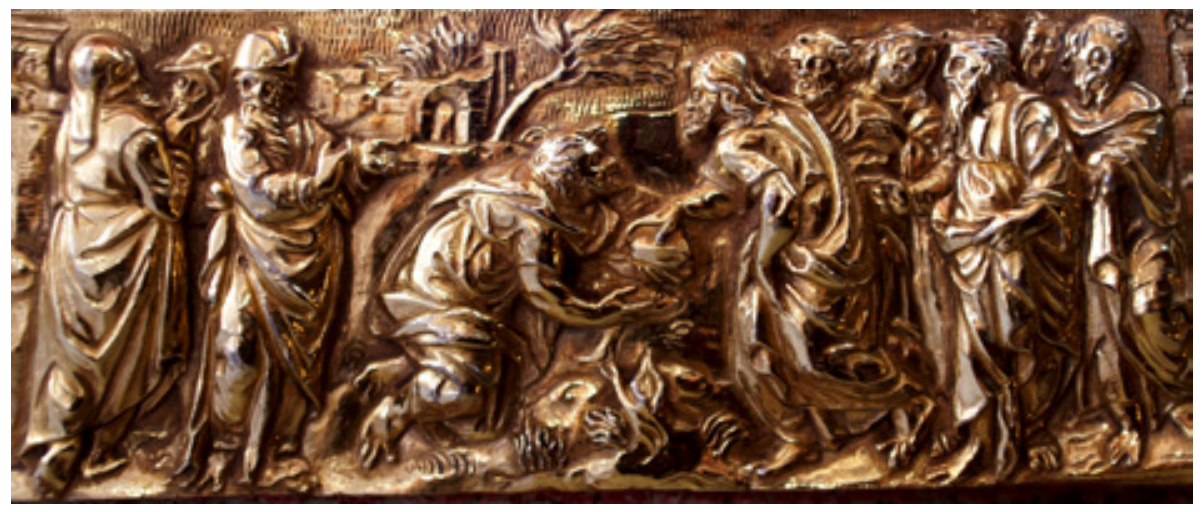

Figura 6. Miguel de Torres Hena, Custodia de asiento, relieve de los discípulos ofreciendo un pez asado a Jesús, 1608, catedral de Morelia (México). Foto: autores. 


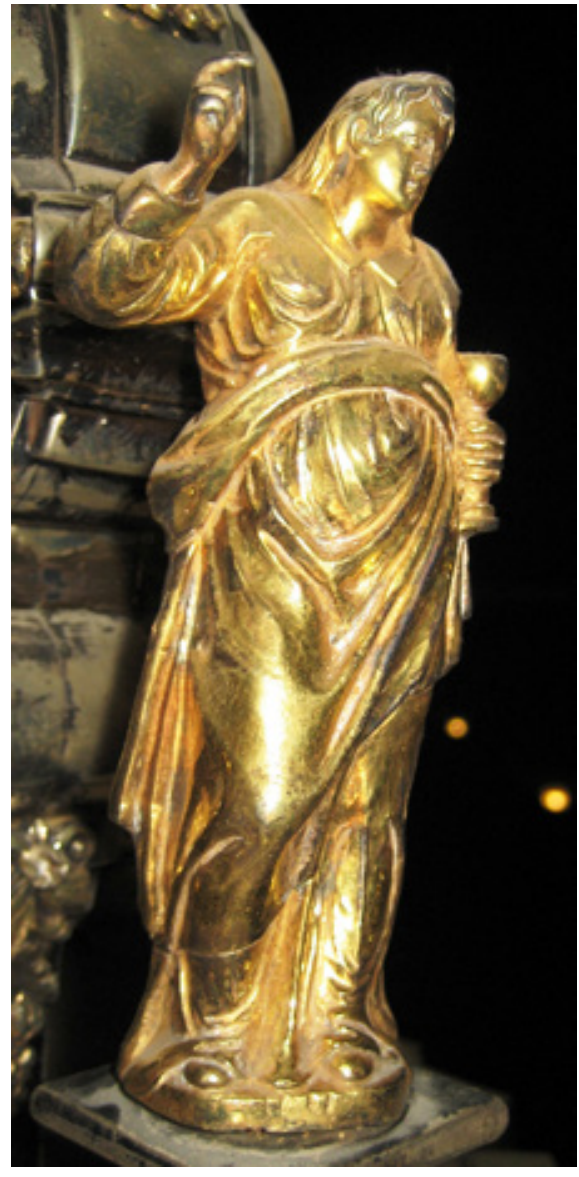

Figura 7. Miguel de Torres Hena, Custodia de asiento, Virtud de la Fe, 1608, catedral de Morelia (México). Foto: autores.

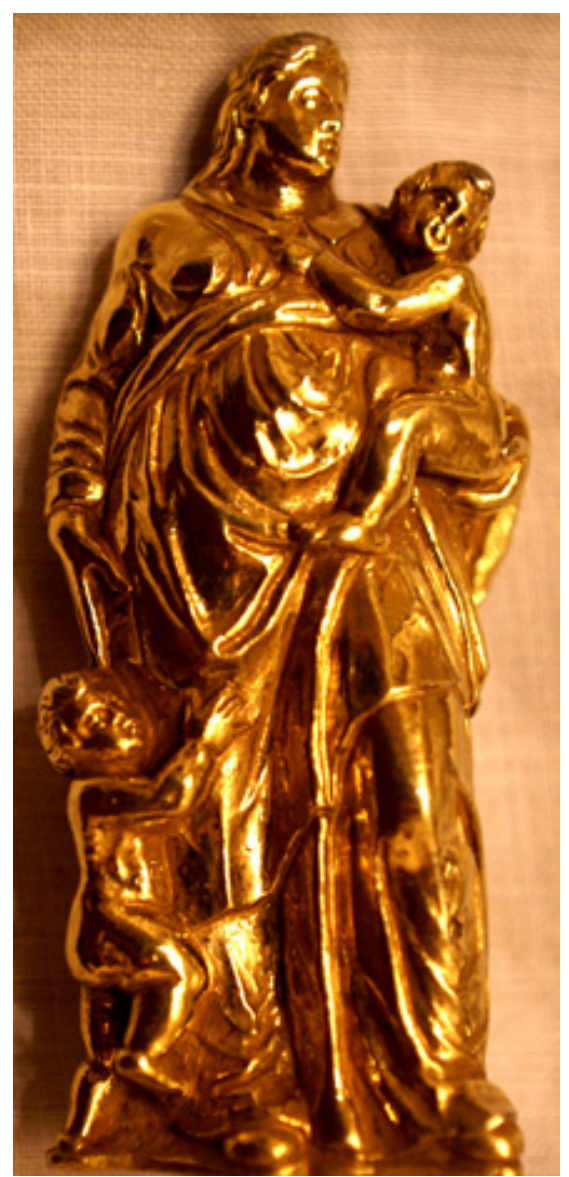

Figura 8. Miguel de Torres Hena, Custodia de asiento, Virtud de la Caridad, 1608, catedral de Morelia (México). Foto: autores. 